\title{
Bagaço Hidrolisado e Ponta de Cana-de-Açúcar (Sacharum officinarum), Associados a Duas Fontes Protéicas, na Engorda de Bovinos em Confinamento ${ }^{1}$
}

\author{
Luiz Rogério Gonçalves Magalhães ${ }^{2}$, Hernan Maldonado Vasquez ${ }^{3}$, José Fernando Coelho da Silva ${ }^{4}$
}

\begin{abstract}
RESUMO - Com o objetivo de avaliar o efeito do bagaço de cana hidrolizado e da ponta de cana-de-açúcar no desempenho de bovinos, 72 novilhos Nelore, com idade média de 18 a 30 meses e $293 \mathrm{~kg} \mathrm{PV}$, foram confinados durante 99 dias. Os tratamentos consistiram em: $40,0 \%$ de bagaço de cana hidrolizado (BAH) e 20,0\% ponta de cana (tratamentos T1 e T4); 20,0 de BAH e 40,0\% de ponta de cana (T2 e T5); e 30,0 de BAH e 30,0\% de ponta de cana (T3 e T6). Duas fontes protéicas: levedura seca, associada aos tratamentos T1, T2 e T3 e farinha de carne mais aditivo (Nutrigen), associada aos tratamentos T4, T5 e T6 também foram usadas. A ingestão média diária de matéria seca (kg/animal), a conversão alimentar e o ganho de peso médio (kg/animal•d) foram para T1, T2, T3, T4, T5 e T6, respectivamente, 4,$01 ; 5,50 ; 5,06 ; 4,50 ; 7,33$; e 12,71, 17,14;13,09;14,79; 8,79; 17,45; e 12,71 e 0,$234 ; 0,420 ; 0,342 ; 0,516$; 0,420 ; e 0,454 . Os animais que receberam farinha de carne mais aditivo (Nutrigem) apresentaram melhor desempenho animal.
\end{abstract}

Palavras-chave: aditivo, farinha de carne, levedura

\section{Hydrolyzed Sugar Cane (Sacharum officinarum) Bagasse and Sugar Cane Tops, Associated with Two Protein Sources in the Fattening of Feedlot Steers}

\begin{abstract}
With the objective to evaluate the effect of hydrolyzed sugar cane bagasse and sugar cane tops in the performance of cattle, 72 Nellore steers, averaging from 18 to 30 months of age and $293 \mathrm{~kg} \mathrm{LW}$ were feedlot for 99 days. The treatment consisted in $40.0 \%$ hydrolyzed sugar cane bagasse (BAH) and 20.0\% sugar cane tops (treatments T1 e T4), 20.0 BAH and $40.0 \%$ sugar cane tops (T2 and T5), and 30.0 BAH and 30.0\% sugar cane tops (T3 and T6). Two protein sources: dried yeast, associated with the treatments T1, T2, and $\mathrm{T} 3$ and meat meal plus additive (Nutrigen), associated to T4, T5 and T6, were also used. The average daily dry matter intake (kg/ animal), the feed:gain ratio ( $\mathrm{kg} \mathrm{DM} / \mathrm{kg}$ gain/animal•d ) and the average weight gains were for T1, T2, T3, T4, T5 and T6, respectively, 4.01, 5.50, 5.06, $4.50,7.33$, and $12.71,17.14,13.09,14.79,8.79,17.45$, and 12.71 and $.234, .420, .342, .516, .420$, and .454 . The animals fed diets with meat meal plus Nutrigen, showed best animal performance.
\end{abstract}

Key Words: additive, meat meal, yeast

\section{Introdução}

O alto preço dos grãos de cereais e suplementos protéicos utilizados na alimentação animal tem estimulado a pesquisa de outras alternativas que atendam as necessidades da produção animal, entre elas o uso de subprodutos agro-industriais. A difusão da prática de confinamento de bovinos, principalmente na entressafra, veio também facilitar a utilização destes subprodutos.

O Brasil é um dos maiores produtores de açúcar e álcool de cana-de-açúcar, com uma área plantada na ordem de 2,5 milhões de ha (IBGE 1980). Especialmente, a região Norte Fluminense possuía, em 1990 , cerca de 162.161 ha plantados com cana-de- açúcar. Dentro desse contexto, vários trabalhos têm procurado otimizar a utilização dos derivados da agro-indústria sucroalcoleira na alimentação animal.

Athassanof (1917), citado por AROEIRA e SANTANA (1979), mostrou as vantagens da canade-açúcar sobre outras forrageiras, em função do seu elevado rendimento e da coincidência da colheita com a época de escassez de forragens. A partir da cana-de-açúcar, a agro-indústria deixa inicialmente, como subproduto, a ponta de cana, cuja a possibilidade de utilização foi demostrada por PEIXOTO (1964). Outro subproduto é o bagaço, que, após a extração do suco, corresponde a aproximadamente $30 \%$ da cana moída e, em grande parte, é usado na própria indústria como fonte energética

\footnotetext{
${ }^{1}$ Parte da Dissertação de Mestrado apresentada pelo primeiro autor, à Universidade Estadual do Norte Fluminense, Campos dos Goytacazes, RJ.

2 Zootecnista, UENF, MS em Produção Animal, CCTA, UENF.

${ }^{3}$ Docente LZNA, CCTA, UENF.

${ }^{4}$ Docente LZNA, CCTA, UENF, 28015-620 Campos dos Goytacazes, RJ, Bolsista do CNPq.
} 
(MATOS, 1987). Entretanto, o bagaço in natura (BIN) é um produto de valor nutricional limitado, devendo ser utilizado após aquecimento sob pressão e vapor. A hemicelulose, por meio deste processo, é quase totalmente solubilizada pelo rompimento das ligações do tipo éster com a liginina, resultando no bagaço hidrolisado (RANGNEKAR et al., 1982).

O bagaço hidrolisado foi estudado com bovinos em confinamento por PATE (1982) e BOIN (1987), que demonstraram a viabilidade do seu uso em até $60 \%$ na ração e encontraram ganhos de 0,820 a 0,960 $/ \mathrm{kg} /$ animal $/$ dia. BERCHIELLI et al. (1989 e 1990) constataram que o bagaço hidrolisado constituiu fonte alternativa para a substituição do capim, em rações para confinamento, quaisquer que fossem as fontes de proteína e energia utilizadas. Em outro experimento, PRADO et al. (1995) não encontraram diferença na comparação entre bagaço hidrolisado e capimelefante em um experimento no qual o bagaço representava $30 \%$ da matéria seca total. Segundo os mesmos autores, o bagaço hidrolisado foi a forma potencialmente mais empregada para se utilizar este ingrediente na ração de bovinos em confinamento.

Paralelamente ao uso de subprodutos agro-industriais na alimentação de ruminantes, várias pesquisas têm procurado encontrar compostos que possam melhorar a eficiência de sua utilização. A própria levedura seca, proveniente de sangria da dorna de fermentação, além de ser fonte protéica de alta qualidade, tem recebido especial atenção pelo fato de sua fração nitrogenada possuir 20 a 30\% de ácidos nucleicos (BOIN, 1987). Segundo NEWBOLD et al. (1995), o uso de levedura como promotora de crescimento foi descrito na literatura em 1925, sabendo-se, contudo, que a levedura exerceu efeito benéfico sobre as bactérias celulolíticas do rúmen.

No presente estudo utilizou-se o aditivo "Nutrigen", composto à base de nucleotídeos que participam de grande variedade de processos bioquímicos, atuando no corpo animal como reguladores estruturais, metabólicos e energéticos. No interior das células, os nucleotídeos cumprem as seguintes funções: incorporação de monofosfatos de ribose ou desoxirribose, respectivamente, nos ácidos nucléicos RNA-DNA, transdução de energia (ATP), parte integrante de coenzimas (AMP), aceptores na fosforilação oxidativa (ADP), reguladores alostéricos da atividade enzimática e segundos mensageiros (cAMP, cGMP).

A diversidade de subprodutos gerados pela agroindústria sucroalcoleira permite uma gama de alterna- tivas que podem ser amplamente utilizadas na alimentação animal, minimizando custos para o produtor.

$\mathrm{Na}$ presente pesquisa, objetivou-se estudar o efeito da utilização de bagaço hidrolisado e ponta de cana-de-açúcar associados a duas fontes protéicas (levedura seca e farinha de carne com aditivo), no desempenho de bovinos em confinamento, bem como estimar a eficiência econômica destes tratamentos.

\section{Material e Métodos}

O presente trabalho foi realizado no Laboratório de Zootecnia e Nutrição Animal da UENF, em parceria com a Usina Santa Cruz, o Banco do Brasil e a C.E.F.A. (Promotores biogenéticos de performances). O experimento foi realizado no período de 12 de setembro a 9 de dezembro de 1995, na Usina Santa Cruz, situada a $11 \mathrm{~km}$ do centro de Campos dos Goitacazes. Este município localiza-se na região norte fluminense, a $21^{\circ} 48^{\prime} \mathrm{S}$ de latitude e $41^{\circ} 20 \mathrm{w}$ de longitude, apresentando $11 \mathrm{~m}$ de altitude. Possui clima Aw tropical (KÖEPPEN, 1948), com temperatura média de 23,2 graus centígrados, precipitação pluviométrica anual média de $1060 \mathrm{~mm}$ e $79 \%$ de umidade relativa média diária. A pluviosidade duranteo período experimental encontra-se na Tabela 1.

Utilizaram-se neste trabalho 72 bovinos machos Nelores não-castrados, com idade entre 18 e 30 meses e peso médio inicial de $293 \mathrm{~kg}$. Os animais foram confinados em baias construídas de madeira e cordoalha de aço, com pisos de terra compactada, tendo área disponível de 18 metros quadrados por animal e cochos de concreto pré-fabricados cobertos, para volumosos, melaço e sal mineralizado. A

Tabela 1- Pluviosidade mensal e total Table 1 - Monthly and total rainfall

\begin{tabular}{lc}
$\begin{array}{l}\text { Mês/Ano } \\
\text { Month/Year }\end{array}$ & $\begin{array}{c}\text { Precipitação pluviométrica (mm) } \\
\text { Rainfal }\end{array}$ \\
\hline $\begin{array}{l}\text { Setembro/95 } \\
\text { September }\end{array}$ & 14,7 \\
$\begin{array}{l}\text { Outubro/95 } \\
\text { Octuber }\end{array}$ & 131,4 \\
$\begin{array}{l}\text { Novembro/95 } \\
\text { November }\end{array}$ & 151,3 \\
$\begin{array}{l}\text { Dezembro/95 } \\
\text { December } \\
\text { Total no ano de } 1995\end{array}$ & 157,3 \\
Total during the year & 905,1 \\
\hline
\end{tabular}


824 Rev. bras. zootec.

água foi fornecida em tanques com sistema de bóia. O cocho para volumoso proporcionava $1,25 \mathrm{~m} /$ animal e o de melaço, $0,16 \mathrm{~m} /$ animal.

Foram utilizados seis tratamentos, cada um com 12 animais. A composição das rações variou em função da proporção de bagaço auto-hidrolisado e ponta de cana e da fonte protéica - levedura e farinha de carne mais o aditivo "Nutrigen". Na Tabela 2, encontra-se a composição percentual dos ingredientes de cada ração expressa na matéria seca (MS).

As rações foram formuladas segundo as normas do NRC (1984), para ganho esperado de 1,0 kg de peso vivo diário, atendendo às exigências recomendadas. A composição das rações é apresentada na Tabela 3 . O bagaço hidrolisado foi tratado à pressão de $17 \mathrm{kgf} / \mathrm{m}^{2}$, por sete minutos, conforme rotina já estabelecida na própria usina. A ponta de cana-deaçúcar, a levedura seca, o melaço e os demais ingredientes foram fornecidos pela usina Santa Cruz, en- quanto que o aditivo foi oferecido pelo fabricante. Antes do início do experimento, obteve-se amostra de cada ingrediente para análise. A distribuição dos animais nos tratamentos foi feita em blocos ao acaso, com base no peso inicial.

Os tratamentos consistiram em T1: $40 \%$ de bagaço hidrolizado (BHA) e $20 \%$ de ponta de cana mais levedura; T2: $20 \%$ de BHA e $40 \%$ de ponta de cana mais levedura; e T3: $30 \%$ de BHA e $30 \%$ de ponta de cana mais levedura. Os outros três tratamentos (T4, T5,T6) compreenderam as mesmas proporções de volumoso porém com a presença de farinha de carne mais aditivo (FCA, Tabela 2).

O período experimental foi programado para ter duração de 99 dias, incluindo os 15 dias de adaptação e três períodos de 28 dias cada um.

Houve um período de adaptação de 15 dias, no qual os animais receberam as respectivas dietas de cada tratamento, sendo os níveis de uréia

Tabela 2 - Composição percentual dos ingredientes das rações (\%MS)

\begin{tabular}{|c|c|c|c|c|c|c|}
\hline & $\mathrm{T} 1$ & $\mathrm{~T} 2$ & T3 & $\mathrm{T} 4$ & T5 & T6 \\
\hline Bagaço hidrolisado & 40 & 20 & 30 & 40 & 24 & 32 \\
\hline Hydrolized bagasse & & & & & & \\
\hline Ponta de cana & 20 & 40 & 30 & 24 & 40 & 32 \\
\hline Sugar cane top & & & & & & \\
\hline $\begin{array}{l}\text { Melaço } \\
\text { Molasse }\end{array}$ & 30 & 30 & 30 & 30 & 30 & 30 \\
\hline $\begin{array}{l}\text { Uréia + S.A* } \\
\text { Urea }+ \text { A. S. }\end{array}$ & 2 & 2 & 2 & 2 & 2 & 2 \\
\hline $\begin{array}{l}\text { Minerais } \\
\text { Minerals }\end{array}$ & 1 & 1 & 1 & 1 & 1 & 1 \\
\hline $\begin{array}{l}\text { Levedura } \\
\text { Yeast }\end{array}$ & 7 & 7 & 7 & - & - & - \\
\hline $\begin{array}{l}\text { Farinha de carne } \\
\text { Meat meal }\end{array}$ & - & - & - & 3 & 3 & 3 \\
\hline $\begin{array}{l}\text { Aditivo g/100kg } \\
\text { Aditive } \mathrm{g} / 100 \mathrm{~kg}\end{array}$ & - & & & 90 & 90 & 90 \\
\hline
\end{tabular}

* Sulfato de amônia ( uréia: S.A. - 9:1)

${ }^{*}$ Ammonium sulphate (urea : A. S. - 9:1)

Tabela 3 - Teor de matéria seca (MS), proteína bruta (PB), extrato etéreo (EE), fibra em detergente neutro (FDN), fibra em detergente ácido (FDA), Ca e $P$ das rações, por tratamento

Table 3 - Content of dry matter (MS), crude protein (PB), ether extract (EE), neutral detergent fiber (FDN), acid detergent fiber (FDA), Ca and $P$ of the diets, per treatment

\begin{tabular}{|c|c|c|c|c|c|c|c|}
\hline \multirow{3}{*}{ Tratamento } & \multirow[b]{2}{*}{ MS\% } & & & \multicolumn{2}{|c|}{$\% \mathrm{MS}(\% D M)$} & \multirow[b]{2}{*}{$\mathrm{Ca}$} & \multirow[b]{2}{*}{$\mathrm{P}$} \\
\hline & & $\mathrm{PB}$ & $\mathrm{EE}$ & FDN & FDA & & \\
\hline & $D M$ & $C P$ & & $N D F$ & $A D F$ & & \\
\hline 1 & 55,70 & 10,33 & 0,44 & 38,00 & 29,00 & 0,23 & 0,12 \\
\hline 2 & 47,36 & 10,93 & 0,45 & 40,06 & 31,02 & 0,30 & 0,15 \\
\hline 3 & 55,06 & 10,62 & 0,44 & 39,30 & 27,90 & 0,26 & 0,13 \\
\hline 4 & 53,53 & 10,26 & 0,48 & 40,94 & 30,64 & 0,33 & 0,21 \\
\hline 5 & 52,59 & 10,75 & 0,49 & 42,34 & 33,28 & 0,39 & 0,23 \\
\hline 6 & 52,99 & 10,50 & 0,58 & 42,01 & 29,76 & 0,36 & 0,22 \\
\hline
\end{tabular}


gradativamente aumentados em três etapas, de acordo com o seguinte esquema: início do experimento, $0,7 \%$; após sete dias, $1,4 \%$; e aos quinze dias, $2 \%$ da mistura uréia mais sulfato de amônia. As rações formuladas para atender as exigências foram fornecidas com excesso de $10 \%$, para que houvesse sobras. Em função da variação de peso e do consumo voluntário, as quantidades de alimento foram reajustadas às necessidades, mantendo-se, no entanto, a relação proporcional dos ingredientes. As rações foram oferecidas duas vezes ao dia, metade pela manhã $(7 \mathrm{~h})$ e outra metade à tarde $(14 \mathrm{~h} 30)$. O melaço foi fornecido uma única vez ao dia $(10 \mathrm{~h})$ e o sal mineral (mistura completa: sulfato de zinco, $3,147 \%$; sulfato de cobre, $0,931 \%$; sulfato de magnésio, $1,068 \%$; sulfato de cobalto, $0,0244 \%$; iodeto de potássio, $0,01284 \%$; fosfato bicálcico, 43,95; e cloreto de sódio, 50,867\%) fornecido à vontade no cocho.

Antes de iniciar a fase de adaptação, os animais receberam anti-helmíntico (Ivermectina) e vitaminas A, D e E. Este procedimento foi repetido após 60 dias nas dosagens recomendadas pelos fabricantes $(1 \mathrm{~mL}$ de Ivermectina para cada $50 \mathrm{~kg}$ de peso vivo, 2.000.000 UI de vitamina A, 500.000 UI de vitamina $\mathrm{D}$ e 550 UI de vitamina E).

Os animais foram pesados no início e no término da fase de adaptação e, posteriormente, a cada 28 dias. Antes de cada pesagem, os animais foram submetidos a período de jejum de 16 horas.

A ponta de cana foi cortada diariamente para ser oferecida fresca, enquanto o bagaço hidrolisado foi processado semanalmente. Os demais ingredientes foram armazenados em galpão coberto, sendo as misturas concentradas preparadas a cada semana.

A ração fornecida, assim como as sobras, foi diariamente pesada para cada tratamento. Semanalmente foram coletadas amostras da ração e das sobras, assim como dos ingredientes. Estas amostras foram agrupadas de forma proporcional, constituindo amostras compostas, acondicionadas em sacos de plástico e congeladas à temperatura de $-10^{\circ} \mathrm{C}$. Posteriormente, foram colocadas em sacos de papel para pré-secagem, em estufa de ventilação forçada, à temperatura de $55 \mathrm{a} 60^{\circ} \mathrm{C}$, por um período de 48 horas. Em seguida, foram moídas em moinho tipo "Willey" com peneira de 30 "mesh", para a realização das análises químicas. As determinações de nitrogênio total, extrato etéreo, cinza, fibra em detergente neutro (FDN) e fibra em detergente ácido (FDA) foram feitas de acordo com SILVA (1990). Realizaram-se as análises de $\mathrm{Ca}$ e $\mathrm{P}$, respectivamen- te, por espectrofotometria de absorção atômica e colorimétrica, a partir de soluções minerais preparadas por via úmida.

O delineamento experimental foi em blocos casualisados, estabelecidos em função do peso inicial dos animais, com doze repetições e seis tratamentos, os quais corresponderam a todas as combinações de fonte protéica e proporção de BAH e ponta de canade-açúcar. O modelo estatístico foi representado pela seguinte equação:

$$
Y i j=\mu+F p i+P k+F p x P i k+b j+E i j,
$$

em que

Yij = é a observação do tratamento i no bloco j;

$\mu \quad=$ é a média geral do experimento;

Fpi = é o efeito da fonte protéica $\mathrm{i}=[1,2]$;

$\mathrm{Pk}$ = é o efeito da proporção de BAH $\mathrm{k}=[1,3]$;

Fpx Pik = é o efeito da interação entre a fonte protéica e a proporção de $\mathrm{BAH}$;

bj = é o efeito do bloco j; e

Eij = é o erro experimental relativo a observação.

Os resultados foram interpretados estatisticamente por meio de análise de variância e as médias dos ganhos de peso comparadas pelo teste Tukey a $5 \%$ de probabilidade.

Para efeito desta análise, considerou-se que as proporções de BAH e ponta de cana são nutricionalmente iguais para os tratamentos $\mathrm{T} 1, \mathrm{~T} 4$; T2 ,T5; e T3, T6.

Para a análise dos custos, foram considerados apenas os valores dos insumos no preparo das rações, não levando em conta outros fatores. Assim, o valor calculado refere-se ao custo de aquisição dos ingredientes.

\section{Resultados e Discussão}

A análise do BAH (Tabela 4), em relação ao teor de matéria seca (MS), mostrou valores constantes, nos três períodos, sendo a média de $40,96 \%$. O mesmo aconteceu com o teor de MO e outros itens analisados, indicando uniformidade no processo de hidrólise do produto.

Os resultados de análise do $\mathrm{BAH}$, em relação ao de MS, foram próximos aos obtidos por PATE (1982), BURGI (1985) e LIMA e ZANETTI (1996). Já o teor médio de PB $(2,13 \%)$ foi superior ao de BURGI (1985) e LIMA e ZANETTI (1996). O teor médio de FDN foi semelhante ao encontrado por BURGI (1985) e superior ao obtido por PATE (1982) e LIMA e ZANETTI (1996). O teor de FDA $(52,25 \%)$ foi inferior ao encontrado por BURGI (1985), enquanto o 
826 Rev. bras. zootec.

teor médio de EE foi ligeiramente superior ao encontrado por esse mesmo autor. Com relação aos valores médios de $\mathrm{Ca}$ e $\mathrm{P}$, os resultados obtidos foram inferiores aos encontrados por LIMA e ZANETTI (1996).

As análises realizadas na ponta de cana (Tabela 4) apresentaram resultados homogêneos, tratando-se de um produto que foi colhido e oferecido diariamente, durante longo período. $\mathrm{O}$ teor de $\mathrm{MS}$, por exemplo, variou muito pouco nos três períodos, tendo média de $35,46 \%$. Em relação ao teor de $\mathrm{PB}$, houve pequeno aumento no decorrer dos períodos (I $=5,42 \%$, II $=5,45 \%$, III $=$ $6,69 \%$ ). Quanto aos outros itens analisados, também ocorreu o mesmo, comprovando que a ponta de cana foi um produto bastante estável durante todo o experimento.

Ainda com relação à ponta de cana, os teores médios de MS e PB foram semelhantes aos encontrados por THIAGO et al. (1982). O valor obtido para FDN foi superior ao de THIAGO et al. (1984), porém, para FDA, houve semelhança entre os valores apresentados por esses autores e os obtidos no presente trabalho. Finalmente, a média encontrada para MO foi inferior à obtida por THIAGO et al. (1984), mas superior à encontrada por AROEIRA e SANTANA (1979).

Os pesos médios iniciais e finais, os ganhos médios diários, os consumos de MS e a conversão alimentar encontram-se na Tabela 5. Observa-se que, apesar da homogeneidade nos pesos médios iniciais, os valores de peso final foram abaixo do esperado para o tempo de confinamento. Pode-se observar o mesmo para o consumo, que foi abaixo do esperado, sendo sua variação bastante alta entre os tratamentos.

As conversões alimentares alcançadas pelos animais nos tratamentos com levedura nos três níveis de BHA (T1, T2 e T3) e com FCA nos níveis de 24 e 32\% de BHA (T5 e T6) estão dentro da faixa relatada na literatura, porém o valor obtido em T4 (FCA e 40\% de BHA) está abaixo dos outros e muito alto em se tratando de bovinos, com este tipo de alimentação.

Os consumos médios de MS, por período e tratamento, constam da Tabela 6 , assim como o consumo médio geral, expresso em $\mathrm{kg} / \mathrm{dia}$ e porcentagem do peso vivo (\%PV). Os consumos médios observados estão entre 2,23 e $46,53 \%$, abaixo do sugerido pelo NRC (1984), para ganho de $1 \mathrm{~kg} / \mathrm{dia}$. Comparando

Tabela 4 - Teor de matéria seca (MS), proteína bruta (PB), fibra em detergente ácido (FDA), fibra em detergente neutro (FDN), $\mathrm{Ca}, \mathrm{P}$, matéria orgânica (MO) e extrato etéreo (EE) dos ingredientes das rações

Table 4 - Content of dry matter (MS), crude protein (PB), neutral detergent fiber (FDN), acid detergent fiber (FDA), Ca, $P$, organic matter (MO) and ether extract (EE) of the diets ingredients

\begin{tabular}{|c|c|c|c|c|c|c|c|c|c|}
\hline \multirow[t]{2}{*}{$\begin{array}{l}\text { Ingrediente } \\
\text { Ingredient }\end{array}$} & $\begin{array}{l}\text { Período } \\
\text { Period }\end{array}$ & $\begin{array}{c}\mathrm{MS} \% \\
D M\end{array}$ & $\begin{array}{l}\text { PB } \\
C P\end{array}$ & $\begin{array}{l}\text { FDN } \\
N D F\end{array}$ & $\begin{array}{l}\text { FDA } \\
A D F\end{array}$ & $\mathrm{Ca}$ & $\mathrm{P}$ & $\begin{array}{l}\mathrm{MO} \\
\mathrm{OM}\end{array}$ & $\mathrm{EE}$ \\
\hline & & \multicolumn{8}{|c|}{$\% \operatorname{MS}(\% D M)$} \\
\hline Bagaço hidrolisado & 1 & 41,34 & 2,35 & 59,14 & 52,39 & 0,1 & 0,05 & 97,88 & 0,53 \\
\hline \multirow[t]{4}{*}{ Hydrolised bagasse } & 2 & 41,18 & 1,74 & 61,56 & 51,27 & 0,1 & 0,04 & 95,94 & 0,53 \\
\hline & 3 & 40,36 & 2,31 & 61,77 & 53,11 & 0,1 & 0,05 & 94,74 & 0 \\
\hline & Média & 40,96 & 2,13 & 60,82 & 52,25 & 0,1 & 0,05 & 96,19 & 0,35 \\
\hline & Mean & & & & & & & & \\
\hline Ponta de cana & 1 & 36,24 & 5,42 & 72,27 & 41,42 & 0,44 & 0,2 & 88,17 & 0,54 \\
\hline \multirow[t]{4}{*}{ Sugar cane top } & 2 & 37,66 & 5,45 & 76,37 & 42,25 & 0,62 & 0,26 & 88,41 & 0,55 \\
\hline & 3 & 32,48 & 6,69 & 75,29 & 43,25 & 0,48 & 0,3 & 89,14 & 0,55 \\
\hline & Média & 35,46 & 5,85 & 74,64 & 42,31 & 0,51 & 0,25 & 88,57 & 0,55 \\
\hline & Mean & & & & & & & & \\
\hline \multirow{5}{*}{$\begin{array}{l}\text { Concentrado de } \\
\text { levedura }{ }^{1}\end{array}$} & 1 & 87,69 & 42,41 & 14,61 & - & 1,4 & 0,8 & 76,98 & 1,3 \\
\hline & 2 & 87,82 & 44,67 & 0,88 & - & 1,8 & 0,7 & 85,06 & 1,1 \\
\hline & 3 & 85,35 & 41,32 & - & - & 1,4 & 0,7 & 85,06 & 1,1 \\
\hline & Média & 86,85 & 42,93 & 14,9 & - & 1,53 & 0,73 & 79,79 & 1,05 \\
\hline & Mean & & & & & & & & \\
\hline \multirow{5}{*}{$\begin{array}{l}\text { Concentrado de } \\
\text { farinha de carne }\end{array}$} & 1 & 85,54 & 82.08 & - & - & 6,4 & 4,7 & 79,66 & 4,65 \\
\hline & 2 & 86,64 & 84,34 & - & - & 6,4 & 3,4 & 79,66 & 4,65 \\
\hline & 3 & 85,7 & 77,39 & - & - & 6,5 & 4,7 & 64,05 & 9,9 \\
\hline & Média & 85,96 & 81,27 & - & - & 5,9 & 4,27 & 73,79 & 7,53 \\
\hline & Mean & & & & & & & & \\
\hline Melaço & $1,2,3$ & 76,01 & 1,8 & - & - & - & - & - & - \\
\hline Molasses & & & & & & & & & \\
\hline
\end{tabular}

${ }^{1}$ Concentrado de levedura (levedura seca, uréia + sulfato de amônia).

2 Concentrado de farinha de carne ( farinha de carne, uréia + sulfato de amônia e aditivo).

1 Yeast concetrate (Yeast, urea + ammonium sulphate).

${ }^{2}$ Meat meal concentrate ( meat meal, urea + ammonium sulphate and aditive). 
MAGALHÃES et al.

Tabela 5 -Peso vivo médio inicial e final $(\mathrm{kg})$, ganho médio diário e consumo de matéria seca e conversão alimentar Table 5 - Average initial and final live weight $(\mathrm{kg})$, average daily gain and dry matter intake feed:gain ratio

\begin{tabular}{|c|c|c|c|c|c|c|}
\hline Item & $\mathrm{T} 1$ & $\mathrm{~T} 2$ & $\mathrm{~T} 3$ & $\mathrm{~T} 4$ & T5 & T6 \\
\hline$\overline{\text { Peso inicial (kg) }}$ & 293 & 290 & 295 & 276 & 280 & 285 \\
\hline Initial live weight & & & & & & \\
\hline $\begin{array}{l}\text { Peso final }(\mathrm{kg}) \\
\text { Final live weight }\end{array}$ & 313 & 326 & 325 & 320 & 315 & 323 \\
\hline $\begin{array}{l}\text { Ganho diário (kg/animal •d) } \\
\text { Daily gain }\end{array}$ & 0,234 & 0,420 & 0,342 & 0,516 & 0,420 & 0,454 \\
\hline $\begin{array}{l}\text { Consumo de MS ( } \mathrm{kg} / \text { animal } \bullet \mathrm{d}) \\
\text { Dry matter intake }\end{array}$ & 4,01 & 5,50 & 5,06 & 4,50 & 7,33 & 5,77 \\
\hline $\begin{array}{l}\text { Conversão alimentar } \\
\text { Feed:gain ratio }\end{array}$ & 17,14 & 13,09 & 14,79 & 8,73 & 17,45 & 12,71 \\
\hline
\end{tabular}

Tabela 6 - Consumo médio diário de matéria seca em cada período e médias dos períodos Table 6 - Average daily dry matter intake in each period and the means for the periods

\begin{tabular}{|c|c|c|c|c|c|}
\hline \multirow[t]{2}{*}{$\begin{array}{l}\text { Tratamento } \\
\text { Treatment }\end{array}$} & \multicolumn{3}{|c|}{$\begin{array}{c}\text { Período }(\mathrm{kg} / \text { animal } \bullet \mathrm{d}) \\
\text { Period }\end{array}$} & \multicolumn{2}{|c|}{$\begin{array}{l}\text { Média } \\
\text { Mean }\end{array}$} \\
\hline & 1 & 2 & 3 & (kg/animal.dia) & $\% \mathrm{PV}(\% L W)$ \\
\hline $\mathrm{T} 1$ & 2,84 & 3,47 & 5,73 & 4,01 & 1,34 \\
\hline $\mathrm{T} 2$ & 5,23 & 5,09 & 6,18 & 5,50 & 1,79 \\
\hline $\mathrm{T} 3$ & 4,08 & 4,60 & 6,50 & 5,06 & 1,63 \\
\hline $\mathrm{T} 4$ & 2,85 & 3,73 & 6,91 & 4,50 & 1,51 \\
\hline $\mathrm{T} 5$ & 7,41 & 6,42 & 8,16 & 7,33 & 2,46 \\
\hline T6 & 4,67 & 5,92 & 6,72 & 5,77 & 1,90 \\
\hline
\end{tabular}

estes resultados com os de outros autores, observase que nos tratamentos T1 e T4, nos quais se tem a maior proporção de BAH na dieta, foram verificados os mais baixos consumos de MS: 4,01 e 4,50 kg/MS/ animal/dia, respectivamente, 1,32 e 1,51\%PV. Este resultado está bem abaixo do valor encontrado por PATE (1982) de 2,89\% do peso vivo (PV), para bovinos recebendo rações com $50 \%$ de BAH e LIMA e ZANETTI (1996), 2,71\% do PV, com rações que continham até $59,34 \%$ de BAH e mais próximos aos dados de OMETO et al. (1990), com $1,79 \%$ do PV. Em relação aos tratamentos T2 e T5, em que a ponta de cana participou em maior proporção, o consumo foi melhor, sendo 1,79 e $2,46 \%$ do $\mathrm{PV}$, respectivamente, no entanto, ainda foi inferior aos valores encontrados por PATE (1982), 2,89\% do PV, o qual obteve BAH de $14 \%$ da MS, e BURGI (1985), 2,76\% do PV, em que o BAH participava com $40 \%$ da MS total. Nos tratamentos T3 e T6, nos quais as proporções de BAH e ponta de cana foram de 30 a $32 \%$, o consumo foi de 1,63 e $1,90 \%$ do PV, sendo inferior aos valores de LIMA e ZANETTI (1996), 2,71\%; BURGI (1985), 2,76\%; e PATE (1982), $2,89 \%$, e pouco mais próximo do valor encontrado por
OMETO et al. (1990), 1,79 e 1,86\%.

Nos resultados de consumo, embora sem análise estatística, pelo fato de os animais terem sido alimentados em grupo, pode-se observar que nos tratamentos em que a fonte protéica foi a farinha de carne mais aditivo, houve, em média, $20 \%$ de melhoria no consumo de MS, em relação aos tratamentos em que a fonte protéica foi a levedura, o que certamente influiu no desempenho dos animais.

Os resultados finais obtidos com o ganho de peso são apresentados na Tabela 7. Observa-se ganho de peso abaixo do esperado, o que pode ser explicado pelo consumo de MS, também abaixo da expectativa necessária para alcançar o ganho desejado, conforme NRC (1984). Outro fator a se considerar foi o fato de ter ocorrido períodos de intensa pluviosidade durante o período experimental, mostrando comportamento atípico para a época na região. Na Tabela 8 , comparando os consumos obtidos com os propostos pelo NRC (1996), verifica-se que, nos tratamentos com levedura nos três níveis de BHA (T1, T2 e T3) e FCA e $32 \%$ de BHA (T6), os ganhos esperados e observados são muito próximos, enquanto, para os tratamentos com FCA e 40 e $24 \%$ de BHA (T4 e T5), 
828 Rev. bras. zootec.

Tabela 7 - Ganho de peso médio por período e média geral Table 7 - Mean weight gain during each period and overall mean Tratamento Período Média geral $(\mathrm{kg})$



\begin{tabular}{llcll}
\hline & \multicolumn{4}{c}{ kg/animalød } \\
T1 & $-0,06$ & 0,527 & 0,413 & 0,234 \\
T2 & 0,542 & 0,274 & 0,443 & 0,420 \\
T3 & 0,33 & 0,288 & 0,408 & 0,342 \\
T4 & 0,422 & 0,672 & 0,464 & 0,516 \\
T5 & 0,392 & 0,378 & 0,488 & 0,420 \\
T6 & 0,437 & 0,553 & 0,369 & 0,454 \\
\hline
\end{tabular}

observa-se grande discrepância. Esta diferença pode ser decorrente da interação de fonte protéica e proporção de $\mathrm{BAH}$, pois, quando se tem a maior proporção de BAH (T4), obtém-se melhor ganho $(0,516 / \mathrm{kg} / \mathrm{animal} / \mathrm{dia}) ;$ o contrário ocorre quando a proporção de BAH é menor (T5).

A análise estatística para ganho de peso mostrou efeito $(\mathrm{P}<0,01)$ da fonte protéica sobre o ganho de peso e também interação da proporção de BAH e fonte protéica (Tabela 9). Nos tratamentos com levedura, houve melhoria no desempenho animal, à medida que a percentagem de BAH diminuiu e a proporção de ponta de cana aumentou ( $\mathrm{T} 1$ - 40\% BAH, $0,262 \mathrm{~kg}$; T3 - 30\% BAH, 0,342 kg; T2 - 20\% BAH, 0,420 kg). Comportamento inverso foi observado nos tratamentos em que se usaram farinha de carne e aditivo, ou seja, à medida que se aumentou a porcentagem de BAH, o desempenho animal melhorou (T5 - 20\% BAH, 0,420 kg; T6 - 32\% BAH, 0,454 kg; e T4 - 40\% BAH, 0,516 kg). Embora T5 e T6 não diferissem estatisticamente, tenderam para melhoria de desem-
Tabela 8 - Ganho de peso médio diário, por tratamento, observado e o esperado segundo NRC (1996), considerando o consumo de matéria seca e a composição das rações

Table 8 - Average daily weight gain, per treatment, observed and estimated according to NRC (1996), considering the dry matter intake and diets composition

\begin{tabular}{lcc}
\hline $\begin{array}{l}\text { Tratamento } \\
\text { Treatment }\end{array}$ & $\begin{array}{c}\text { Ganho observado } \\
\text { Observed gain }\end{array}$ & $\begin{array}{c}\text { Ganho esperado } \\
\text { Estimated gain }\end{array}$ \\
\hline T1 & ------- \\
T2 & 0,234 & 0,160 \\
T3 & 0,420 & 0,420 \\
T4 & 0,342 & 0,350 \\
T5 & 0,516 & 0,210 \\
T6 & 0,420 & 0,640 \\
\hline
\end{tabular}

penho com o aumento da proporção de BAH.

A interação de fonte protéica e a proporção de BAH podem ter sido geradas pelo aumento da taxa de passagem provocada pelo BAH e pela baixa solubilidade ruminal da farinha de carne, ocorrendo maior passagem de frações protéicas para os compartimentos pós-rúmen (BURGI 1985) e promovendo melhor equilíbrio nutricional para o animal. Isto também explicaria o efeito inverso nos tratamentos com levedura, em que o desempenho melhora à medida que se diminui a proporção de BAH. A alta solubilidade da levedura associada a tempo maior da fibra no rúmen contribuiu para melhores condições na fermentação, resultando em melhor desempenho. Reforçando este aspectos, LAVEZZO et al. (1983) preconizaram que o reduzido tamanho das partículas de levedura e sua alta solubilidade ruminal, quando na presença de açúcares, favorece fermentação rápida.

Observando-se a evolução do consumo de MS nos tratamentos com farinha de carne mais aditivo, verifica-se que, embora o consumo inicial no trata-

Tabela 9 - Ganho de peso médio diário, em relação às proporções de volumoso e fontes protéicas Table 9 - Average daily weight gain, on the roughage proportions and protein sources

\begin{tabular}{|c|c|c|}
\hline & \multicolumn{2}{|c|}{$\begin{array}{l}\text { Fonte protéica } \\
\text { Protein source }\end{array}$} \\
\hline Proporção de volumoso & Levedura & Farinha de carne +aditivo \\
\hline Forage proportion & Yeast & Meat meal + aditive \\
\hline BAH:Ponta de cana $(40: 20)$ & (T1) $0,234 \mathrm{cB}$ & (T4) $0,516 \mathrm{aA}$ \\
\hline BAH:Sugarcane top & & \\
\hline BAH:Ponta de cana $(20: 40)$ & (T2) $0,420 \mathrm{aB}$ & (T5) $0,420 \mathrm{bB}$ \\
\hline$B A H:$ Sugarcane top & & \\
\hline BAH:Ponta de cana $(30: 30)$ & (T3) 0,342 b B & (T6) $0,454 \mathrm{~b} \mathrm{~A}$ \\
\hline BAH:Sugarcane top & & \\
\hline
\end{tabular}

Médias, na coluna/linha, seguidas de letras minúsculas/maiúsculas diferentes são diferentes pelo teste Tukey $(P<0,05)$. Means, within a column/row, followed by different small/capital letters are different by Tukey test $(P<.05)$. 
Tabela 10 - Preços dos ingredientes para formulação das rações

Table 10 - Prices of ingredients for the diets formulations

\begin{tabular}{lc}
\hline $\begin{array}{l}\text { Ingrediente } \\
\text { Ingredient }\end{array}$ & $\begin{array}{c}\text { Preço (R } \$ / \text { Ton }) \\
\text { Price }\end{array}$ \\
\hline $\begin{array}{l}\text { Bagaço hidrolisado } \\
\text { Hydrolized bagasse }\end{array}$ & 19,00 \\
$\begin{array}{l}\text { Ponta de cana } \\
\text { Sugar cane top }\end{array}$ & 60,00 \\
$\begin{array}{l}\text { Melaço de cana } \\
\text { Sugar cane molasse }\end{array}$ & 67,00 \\
$\begin{array}{l}\text { Levedura } \\
\text { Yeast }\end{array}$ & 100,00 \\
$\begin{array}{l}\text { Farinha de carne e aditivo } \\
\text { Meat meal and aditive }\end{array}$ & 150,00 \\
Sal mineral & 108,00 \\
Mineral salt & \\
Uréia & 210,00 \\
Urea & \\
\hline
\end{tabular}

mento com 405 BHA (T4) tenha sido menor que em T5 e T6, ainda o tratamento T4 apresentou aumento proporcional mais elevado da ingestão de proteína nos períodos que se seguem $(0,292 ; 0,382$; e 0,709 $\mathrm{kg}$ ), apesar de o consumo médio ser o mais baixo dos três. Este comportamento é exatamente o inverso do que aconteceu nos tratamentos com levedura, ou seja, o melhor desempenho ocorreu no tratamento com levedura e $20 \%$ de BHA (T2), que resultou em melhor consumo médio de proteína, $0,601 \mathrm{~kg} /$ animal.dia comparado com 0,414 em T1 e 0,538 em T3. Isto reforça a hipótese de que, embora o tratamento $\mathrm{T} 4$ tenha resultado em menor consumo de proteína, a provável associação da taxa de passagem mais elevada gerada pelo BAH e a baixa solubilidade ruminal

Tabela 11 - Custo da tonelada de ração e do ganho de 1,0 kg PV/animal•dia, expressos em Real, e conversão alimentar Tabel 11 - Cost of a tonelate of diet and of $1 \mathrm{~kg}$ LW/animal $\bullet$ d, expressed in Real, and feed:gain ratio

\begin{tabular}{lcccc} 
Tratamento & $\begin{array}{c}\text { Custo/ton de ração }(\mathrm{R} \$) \\
\text { Cost/ton of diet }(R \$)\end{array}$ & $\begin{array}{c}\text { Conversão alimentar } \\
\text { Feed:gain ratio }\end{array}$ & $\begin{array}{c}\text { Custo/kg PV } \\
\text { Cost/kg } L W\end{array}$ & $\begin{array}{l}\mathrm{R} \$ / \mathrm{dia} \\
R \$ / \text { day }\end{array}$ \\
\hline T1 & 41,18 & 17,14 & 0,70 & 0,40 \\
T2 & 38,58 & 13,09 & 0,50 & 0,63 \\
T3 & 39,88 & 14,79 & 0,59 & 0,58 \\
T4 & 38,92 & 8,73 & 0,34 & 0,47 \\
T5 & 36,84 & 17,48 & 0,64 & 0,85 \\
T6 & 37,88 & 12,71 & 0,48 & 0,67 \\
\hline
\end{tabular}

da farinha de carne promoveram maior passagem das frações protéicas, resultando em melhor equilíbrio nutricional e, conseqüentemente, maior ganho de peso e melhor conversão alimentar.

Os ganhos de peso encontrados foram baixos quando comparados com os resultados obtidos por outros autores (PATE, 1982; BURGI,1985; GUTMANIS, 1990; OMETO et al., 1990; e LIMA e ZANETTI, 1996).

Os custos apresentados na Tabela 10 referem-se exclusivamente aos preços dos ingredientes utilizados nas rações. Os valores de BAH, ponta de cana, levedura, melaço foram fornecidos pela Usina Santa Cruz. Com relação ao custo do sal mineral, do aditivo e da uréia, foram calculadas as médias, a partir dos preços obtidos no município de Campos dos Goytacazes, em dezembro de 1996. Considerando-se o custo da ração e a conversão alimentar encontrada (Tabela 11), o tratamento T4, além de ter o melhor resultado em termos de ganho de peso, apresentou também o melhor resultado econômico, uma vez que, para cada quilo de ganho, obteve-se custo de 0,34 centavos de Real. É preciso ressaltar que, em virtude de existir grande variação de preço no Brasil em relação à arroba do boi, estes custos devem ser sempre atualizados e analisados em função do preço final obtido com a venda dos animais. 


\section{Conclusões}

Em dietas com $40 \%$ de BAH, a farinha de carne mais aditivo proporcionou melhor desempenho que a levedura.

O desempenho dos animais alimentados com rações de levedura melhorou, à medida que se diminuiu a porcentagem de bagaço hidrolisado na dieta.

Considerando-se os custos da alimentação, o tratamento com FCA e $40 \%$ de BAH (T4) apresentou a melhor relação custo benefício.

\section{Referências Bibliográficas}

AROEIRA L.J.M., SANTANA, J. 1979. Utilização da ponta de cana queimada e da ponta de cana fresca como volumosos, para novilhos confinados, suplementados com melaço x uréia. Pesagro-Rio, Boletim Técnico número, 2 , Niterói , 16 p.

BERCHIELLI, T.T., ANDRADE, P., RIBEIRO, M.V. et al. 1989. Digestibilidade de rações contendo bagaço de cana hidrolisado, suplementadas com farelo de algodão, levedura e rolão de milho. R. Soc. Bras. Zootec., 18(6):456-460.

BERCHIELli, T.T., ANDRADE, P., RIBEIRO, M.V. et al. 1990. Utilização de bagaço de cana hidrolisado e resíduo de amendoim na engorda de bovinos em confinamento. $R$. Soc. Bras. Zootec., 19(2):113-117.

BOIN, C. 1987. Cana-de-açúcar na alimentação de ruminantes. Piracicaba: FEALQ/USP. 47p.

BURGI, M. Produção do bagaço de cana-de-açúcar auto hidrolisado e avaliação do seu valor nutritivo, para ruminantes. Piracicaba, SP, 1985.61p. Dissertação (Mestrado em Zootecnia) - Escola Superior de Agricultura Luis de Queiroz - Universidade de São Paulo, 1985.

GUTMANIS, D. Níveis de Bagaço auto-hidrolisado e de canade-açúcar na alimentação de bovinos confinados. Piracicaba, SP, 1990. 109p. Dissertação (Mestrado em Zootecnia) Escola Superior de Agricultura Luis de Queiroz - Universidade de São Paulo, 1990.

IBGE 1980. Anuário Estatístico do Brasil, IBGE, Rio de Janeiro. $147 \mathrm{p}$.

KÖEPPEN, W. 1948. Climatologia. Buenos Aires, Panamericana, $478 \mathrm{p}$.

LAVEZZO, W., SILVEIRA, A.C., MENDES, O.E.N. et al. Bagaço de cana, resíduo da agricultura tropical como componente de rações para ovinos. Efeitos de diferentes tratamentos sobre os coeficientes de digestibilidade e nutrientes digestiveis totais. In: CONGRESSO DE ZOOTECNIA DO ESTADO DE SÃO PAULO, 3, Botucatu, 1983. Anais... Botucatu, 1983, p. 114.

LIMA, M.L.P., ZANETTI, M.A. 1996. Utilização do bagaço hidrolisado como alimento volumoso para bovinos confinados. R. Soc. Bras. Zootec., 25(3):540-552.
MATTOS, W.R.S. 1987. Utilização do bagaço de cana na alimentação de ruminantes. Piracicaba: FEALQ/USP, p.53-71.

NATIONAL RESEARCH COUNCIL - NRC. 1984. Nutrient requeriments of beef cattle. 6 . ed. Washington. $90 \mathrm{p}$.

NATIONAL RESEARCH COUNCIL - NRC. 1996. Nutrient requeriments of beef cattle. 7. ed. Washington. $242 \mathrm{p}$.

NEWBOLD, C.J., WALLACE, R.J., CHEN, X.B. et al. 1995. Different strains of Saccharomyces cerevisiae differ in their effects on ruminal numbers in vitro and in situ. J. Anim. Sci., 73(6):1811-1818.

OMETO, E.S., LIMA, L.O.P., PAVAN, A.C. et al. Avaliação de bovinos em acabamento com dietas à base de subprodutos da indústria do álcool e açúcar. REUNIÃO ANUAL DA SOCIEDADE BRASILEIRA DE ZOOTECNIA, 27, Campinas, 1990. Anais...Campinas: SBZ, 1990, p.15.

PATE, F.M. 1982. Value of treating bagasse with steam under pressure for cattle feed. Trop. Agric., 59(4):293-297.

PEIXOTO, A.M.A, A. 1964. cana de açúcar como forrageira, cultura e adubação da cana-de-açúcar. Instituto Brasileiro de Potassa, São Paulo, p.307-318.

PRADO, I.N., BRANCO, A.F., ZEOULA, L.M. et al. 1995. Performance and characteristics of feedlot nelore steers, feed 15 or $30 \%$ of whole cottonseed, auto- hidrolized bagasse of sugar cane and sugar cane or elephant grass. Arquivos de Biologia e Tecnologia, 38(2):353-365.

RANGNEKAR, D.V., BADVE, V.C., KHARAT, S.T. et al. 1982. Effect of high-pressure steam treatment on chemical composition and digestibility in vitro of roughages. Anim. Feed. Sci. Tech., 7:61-70.

SILVA, D.J. 1990. Análise da alimentos (métodos químicos e biológicos), UFV, Impr. Universitária. Viçosa, MG, 165p.

THIAGO, L.R.L.S., SILVA, J.M., COSTA, F.P. et al. 1982. O uso da ponta de cana na engorda de novilhos em confinamento, EMBRAPA, CNPGC, Comunicado Técnico, Campo Grande. $10 \mathrm{p}$.

THIAGO, L.R.L.S., SILVA, J.M., COSTA, F.P. et al. 1984. Engorda de novilhos em confinamento utilizando subprodutos de microestilarias de álcool. Pesq. Agrop. Bras., 19(5):657-663.

THIAGO, L.R.L.S., COSTA, F.P., SILVA, J.M. et al. 1986. O uso da ponta de cana na engorda de novilhos confinados, suplementados com milho, sorgo, uréia e feijão-guandu. Pesq. Agrop. Bras., 21(3):317-321.
Recebido em: 10/07/98

Aceito em: 03/12/98 